\title{
Thyrolipoma: A rare entity of the thyroid gland
}

\section{Authors: Betül Ekiz Bilir, Özlem Öztürk², Bülent Bilir ${ }^{3}$ Neslihan Soysal Atile ${ }^{1}$, Hakan Özkan ${ }^{4}$}

Hospital: 1 Tekirdag State Hospital, Endocrinology Department, Tekirdag, Turkey

2 Tekirdag State Hospital, Pathology Department, Tekirdag, Turkey

3 Namik Kemal University, Medical Faculty, Internal Medicine Department, Tekirdag, Turkey

4 Tekirdag State Hospital, General Surgery Department, Tekirdag, Turkey

\section{INTRODUCTION}

Thyrolipoma (focal adenolipoma of thyroid gland with coexistence of mature adipocytes and thyroid follicular cells in a capsulated nodule) and thyrolipomatosis (diffuse infiltration of the thyroid gland with mature adipose tissue) are rarely encountered pathologies in daily practice. Because of their relatively outer localization in the thyroid gland and its fatty nature mimicking parathyroid glandsa, they might be misdiagnosed as parathyroid glands intraoperatively. We reported a case of small thyrolipoma incidentally diagnosed in a multinodular goiter patient.
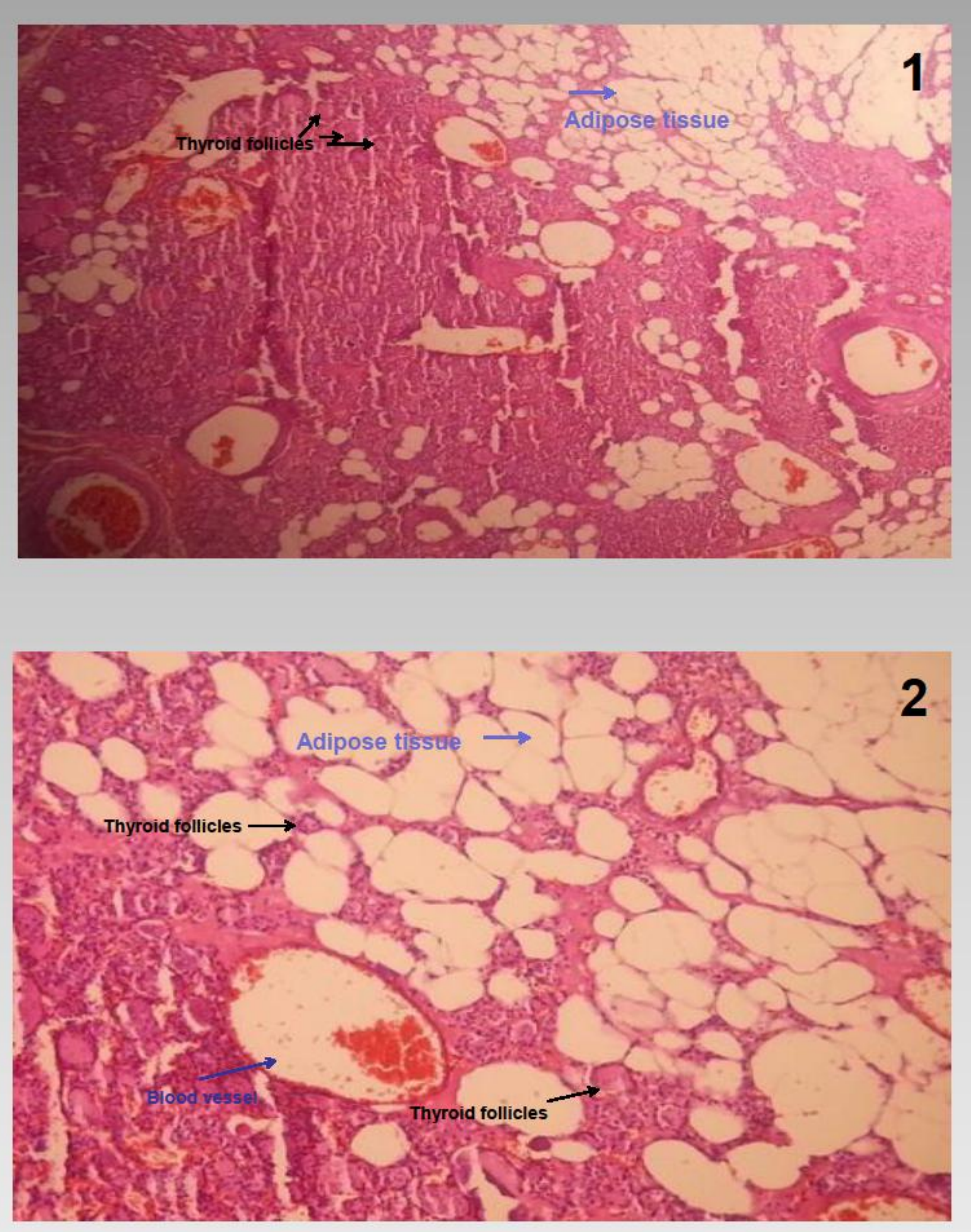

\section{CASE REPORT}

A 56 year-old man was admitted to our out-patient clinics with the complaint of a lump in his left cervical region. His thyroid function tests were normal. Thyroid autoantibodies were negative. In physical examination, a mobile soft nodule of about $4 \mathrm{~cm}$ in the left lobe was realized. In thyroid ultrasonography, multiple nodules with a maximum dimension of $45 \times 30 \mathrm{~mm}$ were reported. No pathological lymph nodes were detected. In fine needle aspiration biopsy of the biggest nodule, benign thyrocytes with the presumption of cystic colloidal nodule were reported. Because of the hugeness of the nodule and multiple nodular nature, total thyroidectomy was performed. In thyroidectomy pathology, bilateral multinodular hyperplasia was reported. In right lobe of the thyroid gland, in a 9x6 $\mathrm{mm}$ subcapsularly located clearly defined marginated nodule, which is reported as a thyrolipoma, mature adipocytes between the colloidal material and thyroid follicles were detected. At the staining of this nodule immunohistochemically with TTF-1 (Thyroid Transcription Factor-1), there was positive staining with TTF-1 in the nuclei of the thyrocytes surrounding the follicles ruling out any intrathyroidal parathyroid gland. No adipose tissue infiltration other than this lesion was detected at the microscopic assessment of the remaining thyroid gland. The patient recovered well after surgery and levothyroxine replacement therapy was initiated.

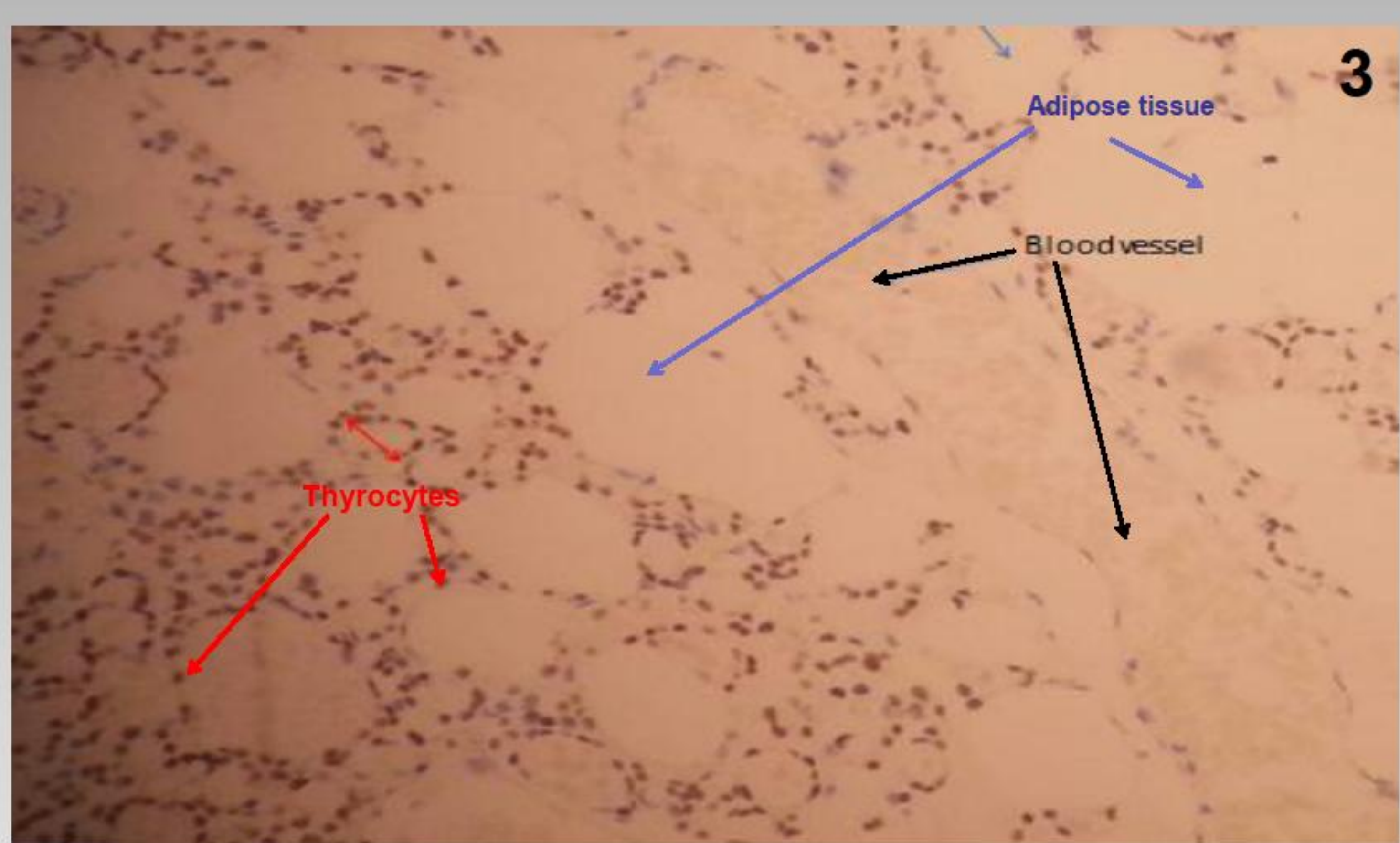

Figure 1: Mature adipose tissue groups between the thyroid follicular structures in a colloidal nodule (4x10 Haematoxylin-Eosin Staining)

Figure 2: 10x10 Haematoxylin-Eosin Staining

Figure 3: TTF-1 immunohistochemical staining highlighting the thyrocytes' nuclei (10x10 TTF-1 Staining)

\section{CONCLUSIONS}

The occurence of mature adipose tissue between the thyroid follicles in the thyroid parenchyma is a very rare condition. Thyrolipomas are rare, benign, biologically inactive tumoral lesions of the thyroid gland. Due to their usual localization and fatty structure, they might be erroneously supposed as parathyroid glands macroscopically.

\section{REFERENCES:}

a Bedir R, Yurdakul C, Güçer H, Sehitoğlu I, Mürtezaoğlu A.R., Aydin I. A retrospective analysis of thyroid lesions containing mature adipose tissue. Dicle Medical Journal 2014;41(2):380-4

10.5798/diclemedj.0921.2014.02.0435 